\title{
O presente como tempo da tradição: a poesia de cordel contemporânea do Maestro Rafael Brito
}

The present as a tradition time: the contemporary cordel of Maestro Rafael Brito

El presente como tiempo de tradición: La poesía de cuerda contemporánea del maestro Rafael Brito

DOI: https://doi.org/10.1590/1809-5844202119

\section{Maria Gislene Carvalho Fonseca ${ }^{1}$}

http://orcid.org/0000-0003-3201-1946

${ }^{1}$ (Universidade Federal de Ouro Preto, Instituto de Ciências Sociais e Aplicadas, Departamento de Jornalismo. Mariana - MG, Brasil).

\section{Resumo}

Este trabalho é uma proposta inicial sobre o tema do presente na discussão da tradição, a partir da reflexão sobre a poesia de cordel, olhando para o trabalho do Maestro Rafael Brito, poeta de FortalezaCE. Rafael é jovem, escreve diversos tipos de poesia, e é mais conhecido por sua produção de cordel, à qual ele se refere de modos "tradicionais”, performando-a com a utilização de recursos midiáticos do presente. Discutimos a ideia de tradição, tradições e tradicionalidade a partir das propostas sobre narrativa de Ricoeur (2010) e analisamos o trabalho de Rafael través de entrevistas e do conteúdo de seu blog na Internet. Observamos que o Maestro é visto como uma promessa de futuro deste cordel "tradicional”, ainda que traga inovações para a historiografia da poesia. Mesmo assim, permanece distante das transformações e de embates políticos que desestabilizariam as narrativas oficiais que reivindicam tradições imutáveis.

Palavras-chave: Cordel. Memória. Tradição. Presente. Maestro Rafael Brito.

\section{Abstract}

This paper is an initial propose about the present in the discussion of tradition, from the reflection on the poetry of cordel in Maestro Rafael Brito, poet from Fortaleza-CE. Rafael is young, writes many kinds of poetry, but is best known for his cordéis, which he refers to in traditional ways, though he performs it using the media resources of the present. We discuss the idea of tradition, traditions and traditionality from Ricoeur's (2010) narrative proposals and analyze Rafael's work through interviews and the content of his blog on the Internet. We observe that the Maestro is seen as a promise of the future of this "traditional" cordel, although it brings innovations of the poetry 
historiography. But it is still far from the transformations and political clashes that would destabilize official narratives claiming unchanging traditions.

Keywords: Cordel. Memory. Tradition. Present. Maestro Rafael Brito.

\section{Resumen}

Este articulo es una propuesta inicial sobre el tema del presente en la discusión de la tradición, a partir de la reflexión sobre la poesía de cordel, mirando la obra del maestro Rafael Brito, poeta de Fortaleza-CE. Rafael es joven, escribe varios tipos de poesía, pero es mejor conocido por su producción de cordéis, a la que se refiere de manera tradicional, aunque lo realiza utilizando los recursos mediáticos del presente. Discutimos la idea de tradición, tradiciones y tradicionalidad de las propuestas narrativas de Ricoeur (2010) y analizamos el trabajo de Rafael a través de entrevistas y el contenido de su blog en Internet. Observamos que el Maestro es visto como una promesa del futuro de este cordel "tradicional”, aunque trae innovaciones de la historiografía poética. Pero aún está lejos de las transformaciones y los enfrentamientos políticos que desestabilizarían las narrativas oficiales que afirman tradiciones inmutables.

Palabras-clave: Cordel. Memoria. Tradición. Presente. Maestro Rafael Brito.

\section{Introdução}

Os temas relacionados à tradição costumam ser imediatamente associados a fenômenos do passado. Mas essa relação direta exclui a dimensão do tempo presente, da continuidade para que um fenômeno seja considerado "tradicional”. Isso não implica um engessamento de tais fenômenos, que os manteriam fixos, "originais" e "puros”. Em vez disso, eles se constituem como tradicionais nas transformações que possibilitam a sua permanência.

O fenômeno da poesia de cordel é tensionado constantemente, a partir da ideia de tradição, sobre suas transformações. Que elementos definidores precisam ser mantidos e que mudanças podem ou não ser aceitas para que uma poesia seja denominada de cordel. O que, de certa forma, configura um prejuízo conceitual ao cordel, como linguagem que é formada por performances, imagens, sons, formas e estruturas poéticas, por mercados editoriais e pela cultura midiática. Como uma classificação, a definição de cordel tem consequências positivas para os recortes e delimitações metodológicas, mas impede uma compreensão aprofundada da dialética entre inovações e continuidades que alcançam o fenômeno.

Para refletir sobre essa dimensão temporal e sobre transformações que ampliam a compreensão do cordel, acompanhamos as produções do poeta, músico e ator que assina como Maestro Rafael Brito. O poeta é cearense, nasceu em 1995 e é reconhecido pelos outros poetas conterrâneos como “uma promessa do cordel cearense”. Há uma valorização das produções de Rafael por parte de poetas que encontram nele uma ideia de continuidade de uma manifestação cultural que fora, muitas vezes, “desenganada” por estudiosos da literatura.

Nesta discussão, temos como referência teórica a proposta de Ricoeur (2010) sobre tradição, tradições e tradicionalidade. A partir dessa ideia, abordamos a dimensão da 
memória, que nos permite compreender o cordel como um fenômeno múltiplo, fluido, vivo, que aciona modos sinestésicos de experienciar a poesia. Realizamos, então, entrevistas com o poeta e acompanhamos sua inserção em feiras e eventos editoriais, com ênfase na Bienal Internacional do Livro de São Paulo, em 2016. A partir dos seus relatos sobre suas produções e das atividades que acompanhamos, podemos analisar suas práticas, com relação aos modos pelos quais ele convoca a ideia de tradição, tomando como referência o que conhecemos sobre as definições de cordel como fenômeno cultural e comunicacional. Observamos, assim, suas relações com o passado e com o presente.

\section{Poesia de cordel: um fenômeno de tradições}

O cordel é uma manifestação cultural. Pode ser compreendido como prática literária, como fenômeno de sociabilidade, como forma de (e objeto de estudos do campo da) Comunicação. É uma referência de arte que aponta para a transmissão de memórias e tradições do Nordeste brasileiro. Mas seu trajeto histórico, social e político transita por uma grande diversidade de espaços físicos e dialoga com muitas outras manifestações culturais.

Assim, podemos dizer que o cordel é o resultado de uma série de diálogos e que ele precisa se manter aberto para continuar existindo. O que acontece é que para muitos poetas e pessoas envolvidas com a poesia, há regras muito rígidas que definem sua forma e que devem ser seguidas para que uma manifestação possa ser chamada de cordel. Nesses casos, as transformações são tomadas como um prejuízo à pureza cultural e à necessidade de manutenção de uma existência que deve ser preservada.

Por isso, para entendermos a poesia de cordel, passamos a um movimento de compreensão conceitual de memória e tradições, que estão comumente associadas a estudos do passado, mas que são fundamentais para um trabalho de reflexão sobre os sentidos do cordel contemporâneo. Há uma constante dialética entre presente e passado nesta manifestação que se apresenta como uma recorrente disputa de sentidos sobre o que deve ser mantido e o que pode ser transformado.

Em Fonseca (2019), por exemplo, os poetas improvisadores de Campina Grande explicam que para ser um bom poeta, é preciso saber combinar o conteúdo com uma métrica perfeita. Essa ideia é reforçada por Silva (2014), presidente da Academia Brasileira de Literatura de Cordel (ABLC). O poeta e pesquisador apresenta e descreve 35 modalidades de versos ${ }^{1}$, cujos conteúdos podem ser classificados como literatura de cordel. Para isso, as estrofes precisam seguir o que ele chama de "primor das rimas, com a beleza rítmica e a preciosidade sonora” (SILVA, 2014, p. 41). Tal definição está de acordo com aquilo que aparece no catálogo de estudos sobre “Literatura Popular em Verso” da Fundação Casa de

1 Quadra, ligeira, parcela ou carretilha, sextilha, gemedeira, setilha, quadrão, quadrão à beira mar, quadrão mineiro, quadrão paraibano, dez a quadrão, décimas, quadrão de meia quadra, mourão de cinco linhas, mourão de seis linhas, mourão de sete linhas, mourão trocado, mourão caído, mourão voltado, mourão perguntado, beira-mar mourão, martelo agalopado, galope à beira-mar, galope alagoano, galope miudinho, dez de queixo caído, Brasil caboco, mote, oitavão rebatido, nove palavras por três, nove palavras por seis, toada alagoana, gabinete, dezoito linhas, embolada. 
Rui Barbosa (1973), cujos autores - Cavalcanti Proença, Orígenes Lessa, Antônio Houais, e Manuel Diegues Junior - são as referências para Silva (2014).

O que muitos desses poetas e folcloristas acadêmicos desconsideram é que não é possível prender e engessar uma manifestação cultural para que ela permaneça. Se ela não for vivida e, portanto, reinventada, adaptada às práticas sociais dos indivíduos, ela enfraquece e tende a desparecer. Assim, nossa discussão sobre tradição tem foco no presente e nas transformações poéticas que situam o cordel em uma linha de continuidades e de inovações.

O cordel brasileiro é poesia. Pode ser apresentado impresso, e sua forma base acontece na voz. Segundo os estudos de Lemaire (2010), Santos (2010) e Abreu (1993), já tínhamos manifestações poéticas no Nordeste Brasileiro quando os cordéis portugueses chegam ao Brasil. Havia cantoria acompanhada por viola que viajava com os poetas contando as novidades de uma cidade a outra nas feiras do interior.

Quando chegam ao Brasil, com a coroa portuguesa, os folhetos literários que circulavam pela Metrópole e as máquinas impressoras que permitiram a criação de uma imprensa nacional foram incorporados à forma poética oral, já comum por essas terras. $\mathrm{O}$ que houve aqui foi um diálogo, um híbrido que se fez entre as manifestações culturais e que resultou no que, convencionalmente, chamamos hoje de cordel: a poesia oral impressa em folhetos.

Segundo Lemaire (2008), o termo “cordel”, como herança ibérica, é instituído no contexto histórico da Ditadura Militar brasileira com o intuito de definir-se, a partir da noção de folclore, uma cultura original brasileira. Desta forma, o que era chamado de folheto, de poesia, de cantoria, passa a ser identificado pelo nome "cordel”, como referência às cordas nas quais eram expostos os seus equivalentes em Portugal. Por essa ideia, as perspectivas tomadas como oficiais e contadas pela Fundação Casa de Rui Barbosa (1973) e pela Academia Brasileira de Literatura de Cordel (2014) consideram que o cordel brasileiro seria um produto de origem portuguesa.

Essas definições já aceitas sobre o $\operatorname{cordel}^{2}$ nos dizem de um produto cultural, comunicativo, que integra texto e voz, mas que não estaria restrito a uma forma poética. Em vez disso, nos sugere Carvalho (2002), que o cordel é mais que os versos. Trata-se de uma forma de ver o mundo. A partir disso, digo aqui que o cordel é um narrar do mundo, um fenômeno fluido. Indisciplinado e, portanto, impossível de ser definido em si mesmo. Temos sempre que o cordel tem um "algo a mais" que o torna sempre impreciso e sempre maior que definições.

É possível pensarmos o cordel por uma dimensão midiática. Entendendo que:

A mídia pode ser apresentada como um lugar de apontamento de sentido, de estabelecimento de formas interativas de criação e de partilhamento de representações e de (re)interpretação de experiências, de vinculação, de junção, de formação de elos, de instrumentação. Por outro lado, a mídia também afigura-

2 São as referências convocadas em disciplinas que estudam "literatura popular em verso" nas universidades, em seus cursos de Letras. 
se como o caráter de transmissividade e de reprodutibilidade, um modo de estabelecimento de temporalidades, um tipo de solicitação de disponibilidade aos sujeitos para o compartilhamento de experiências, uma maneira de estabelecimento de contatos e de estruturação de sentidos (ANTUNES; VAZ, 2006, p. 44-45).

O cordel, então, figura neste espaço. Da organização do tempo em uma narrativa que é, ao mesmo tempo, lugar de transmissão e elemento de memória. Nos folhetos, nas declamações, nas performances, nos versos enviados por mensagem de celular ou postados em redes sociais, o cordel, em suas diversas formas, é um espaço de compartilhamento, de trocas de experiências e de conhecimentos. E é aí que seu entendimento se faz tão relevante para os estudos da Comunicação.

O cordel é como um pássaro beija-flor. Que bate as asas em uma velocidade impossível de ser acompanhada pelos olhos humanos. Assim são as publicações do que chamamos de cordel, ou que consideramos ter a chamada estética do cordel. É poesia cantada, é letra, é imagem. É folheto, é voz, é ambiência, é tempo. Tempo de declamação, tempo do qual emerge e o que faz emergir. São poetas, são ouvintes, são pesquisadores e colecionadores. E cada situação comunicativa da qual emerge a poesia tem esses elementos se materializando de formas distintas e constituindo novas narrativas (FONSECA, 2019, p. 75)

O cordel é uma multiplicidade linguística, semiótica, cultural que se convencionou chamar de popular, como se fosse algo simples, pequeno, menor. Talvez ele seja mesmo popular, se pensarmos na disputa de sentidos que constitui sua existência e linguagem. Uma busca constante por afirmação e legitimação literária e midiática. É uma poesia que emerge e registra o cotidiano, pois mesmo os versos que não se propõem a ser relatos referenciais de um real trazem as marcas experienciais dos poetas e, de alguma forma, versam inferencialmente sobre situações possíveis.

Nossas reflexões versam sobre formas poéticas, que podem ser impressas ou não, e que estão baseadas na oralidade. Declamadas sozinhas ou acompanhadas por violas. Criadas e memorizadas ou improvisadas. Individuais ou em grupo. Complementares ou em disputa. Rimadas e ritmadas em quadras, sextilhas, setilhas, décimas ou versos alexandrinos. Se impressos, as imagens da capa são xilogravuras (mais comumente associadas a essa produção poética, mas não necessariamente definidoras), fotos ou ilustrações que sintetizam a história narrada. Apresentadas em palcos, teatralizadas, divulgadas em redes sociais, vendidas no e-commerce, apresentadas na televisão, viralizadas no YouTube ou cantadas em rodas de brincantes. Tais práticas compõem um leque de manifestações que apontam justamente para a impossibilidade de fechar o cordel em uma característica definidora, mas nos oferecem uma ampla gama de fenômenos em constante transformações para serem estudados e 
reconhecidos em sua importância narrativa, política, cultural. Porque contam histórias, carregam marcas de tempos, configuram tradições.

\section{Do passado à promessa de futuro: memória e tradições}

Memória e tradição são elementos da narrativa que acionam as relações do tempo e da produção de sentidos, atravessando os três modos da experiência mimética. São parte do mundo prefigurado, que antecede a intriga, constroem sentidos na composição da intriga e retornam ao mundo pela perspectiva dos públicos.

Tratamos de memórias coletivas - com todas as dificuldades epistemológicas reconhecidas e apontadas conceitualmente - em diálogo com as memórias individuais, como aborda Ricoeur (1999), que é singular, tem vínculo com a consciência do passado e proporciona uma noção de orientação com relação ao tempo. Assim, ela é tratada aqui como "aquelas lembranças compartilhadas que perfilam a identidade étnica, cultural ou religiosa de uma coletividade dada” [tradução livre] (RICOEUR, 1999, p. 17), integrando sentidos e interpretações.

A oralidade, segundo Zumthor (1993), é um elemento muito importante para as memórias coletivas, que encontram na voz uma articulação da presença.

As vozes cotidianas dispersam as palavras no leito do tempo, ali esmigalham o real; a voz poética os reúne num instante único - o da performance -, tão cedo desvanecido porque se cala; ao menos produz-se essa maravilha de uma presença fugidia, mas total. (ZUMTHOR, 1993, p. 139).

A voz poética, para Zumthor (1993), é profecia - que projeta os acontecimentos - e memória, que lhe oferece permanência no tempo. Considera também a memória coletiva como fonte de saber, enquanto a memória individual estaria no âmbito da aptidão para esgotar e enriquecê-la, o que também aponta para o duplo fluxo do qual trata Ricoeur (1999), que coloca memórias coletiva e individual em relação, instituindo-se mutuamente.

A memória, a partir destas reflexões, aponta Zumthor (1993), envolve toda a existência e mantém o presente na continuidade do tempo. Mesmo sob a forma de poesia, porque carrega nela um saber e o reconstrói continuamente, manifestando-se em atos de enunciação por parte dos intérpretes, que fazem referência às coleções de lembranças coletivas que "sem cessar, ajusta, transforma, recria” (ZUMTHOR, 1993, p. 142). Assim, as artes são compostas e compõem memórias - individuais em artistas e públicos e coletivas, que se retroalimentam.

O cordel é um lugar onde a disputa de sentidos pode ser identificada na negociação entre as manifestações de memória e de esquecimento, considerando que ambos estabelecem uma relação dialética. Temos deste modo, segundo Ricoeur (2007, p. 455), uma ideologização da memória, ou seja, "uma forma ardilosa de esquecimento, resultante do desapossamento dos atores sociais do seu poder originário de narrarem a si mesmos”, o que configura a ideia 
de memória forjada. O cordel aciona os movimentos das tradições pela memória dos poetas posta em relação com a memória coletiva do público.

Essa memória não está relacionada apenas ao passado, mas se projeta em continuidade, com a ideia de que as tradições se mantenham. Não se trata da criação de uma tradição "nova”, mas de sua permanência a partir das projeções de futuro. Compreendemos isso a partir dos conceitos de "horizonte de expectativa” e "espaço de experiência” de Koselleck, apontado por Ricoeur (1999) como “o conjunto de heranças do passado cujas pegadas sedimentadas constituem em certo modo o solo em que descansam os desejos, os medos, as previsões, os projetos e, em resumo, todas as antecipações que nos projetam para o futuro"3 (RICOEUR, 1999, p. 22). A valorização e o reconhecimento de jovens poetas, cantadores, cordelistas, repentistas na atualidade se apresentam como esse horizonte de expectativa, que rompe com a ideia de morte da poesia de cordel.

A memória é "guardada” e mantida para a construção de uma ideia de tradição. Comumente, é tratada como uma estagnação dos movimentos culturais, como algo a ser preservado para a referência a identidades - também fixas. Essa ideia de tradições engessadas é defendida por poetas que compreendem que essas tradições são a representação da história e que precisam ser mantidas - ainda que sustentadas por encenações, mas é também tratada com desprezo por outros que entendem tradição como um passado morto. Ambas mantêm as amarras conceituais e históricas que unificam a experiência, a vivência e as memórias como definidoras de identidades do passado. Seja para permanecer no passado, seja para negá-lo.

Hobsbawm e Ranger (2012) realizam um estudo sobre as “tradições inventadas”, ou seja, hábitos e costumes que foram reforçados em narrativas conduzidas por instituições de poder para que permanecessem e se fizessem reconhecidas como tradições/identidades de comunidades específicas. O que percebemos dos estudos dos autores é que parece que há tipos de tradições que podem ter surgido "naturalmente” e outras que são construídas pelos interesses de alguns grupos de poder. É possível pensar em tradições inventadas por uma escolha voluntária e pela demarcação das características que devem ser mantidas.

Mas no sentido das tradições inventadas, estas incluem tanto as tradições marcadas em suas “origens” quanto aquelas mais difíceis de serem definidas e localizadas temporalmente.

Por tradição inventada entende-se um conjunto de práticas normalmente reguladas por regras tácitas ou abertamente aceitas; tais práticas, de natureza ritual ou simbólica, visam inculcar certos valores e normas de comportamento através da repetição, o que implica, automaticamente, uma continuidade em relação ao passado. Aliás, sempre que possível, tenta-se estabelecer continuidade com um passado histórico apropriado (HOBSBAWM; RANGER, 2012, p. 12).

3 "El conjunto de herencias del pasado cuyas huellas sedimentadas constituyen en cierto modo el suelo en el que descansan los deseos, los miedos, las previsiones, los proyectos $u$, en resumen, todas las anticipaciones que nos proyectan hacia el futuro" (RICOEUR, 1999, p. 22). 
Segundo os autores, a invenção de tradições responde a processos de ritualizações e formalizações como forma de referirem-se ao passado, com imposições de repetição. É o que acontece, por exemplo, quando práticas culturais são teatralizadas com fins comerciais, o que faz com que seus sentidos rituais se percam, por serem retiradas de seus elementos referenciais. Essas tradições que são “criadas” sem referentes na memória coletiva seriam usadas para ideais unificadores de identificação. Deste modo, uma performance da tradição a partir da repetição de comportamentos por parte dos poetas faz parte das definições fechadas sobre o cordel. Tanto quanto exige-se a métrica, observa-se como um ou uma poeta se relaciona com tal performance. Uma vez que essa imagem construída é desestabilizada, ou questionada, e as poetas passam a ter sua atuação questionada.

As tradições decorrem das memórias e, como tal, são fluidas, móveis, construídas e ideologicamente organizadas. "Nas longas durações, a obra de memória constitui a tradição. Nenhuma frase é a primeira. Toda frase, talvez toda palavra, é aí virtualmente, e muitas vezes efetivamente, citação” (ZUMTHOR, 1993, p. 143). A ideia da preservação precisa ser ponderada para considerar que a existência de uma prática cultural como tradição só existe enquanto faz sentido para a comunidade que a pratica. Assim, as tradições e os processos de tradicionalidade, como um conjunto de práticas sociais são atravessadas por outros elementos produtores de sentidos, como a cultura, a economia, as artes, as experiências coletivas de um modo geral.

Carvalho (2005) aponta que essa discussão, em estudos sobre cordel, que busca origens, raízes, explicações para a formação de “espíritos da nação” seria uma prática elitista, de uma cultura romantista e de correntes de estudos folcloristas. A retomada de estudos que buscam compreender as tradições estaria relacionada a reações de culturas locais aos "exageros da globalização”. Interessa a ele os embates dialéticos entre tradição e contemporaneidade. Para Carvalho (2005), a ideia de tradição é tomada como

Práticas que se inserem em uma longa duração. É o que fica do que uma geração transmite para outra, evidentemente, com perdas, substituições e lacunas. A tradição é esse lastro comum de experiências (e vivências) de determinados homens em um determinado tempo e lugar (CARVALHO, 2005, p. 8).

Zumthor (2010) fala das tradições em um sentido que decorre da ideia de movência das obras, ou seja, sua potencialidade de trânsito, de existência e repercussão a partir dos públicos como novos narradores. Isso se aplica às performances artísticas, mas também às performances que dizem das representações dos papéis do cotidiano e de formas de conhecimento. "Ela se sucede dialeticamente a si mesma, em constante reorientação de escolhas existenciais, alterando-se a cada vez que nela ressoa a totalidade de nosso ser-nomundo” (ZUMTHOR, 2010, p. 282).

Segundo Zumthor (1993), a tradição é uma série aberta em constante transformação, nas quais ocorrem as performances. No sentido da movência, abre a ideia da intervocalidade 
que, como a intertextualidade, refere-se às trocas e diálogos que acontecem no âmbito da oralidade. A ideia de tradicionalidade, das tradições em fluxo de movimentação, são criações contínuas em diálogo, atualizando-se de acordo com as transformações midiáticas, culturais, políticas, econômicas, sociais que interferem nas vidas e nas práticas cotidianas das pessoas, que o tempo todo ressignificam os sentidos.

Assim, retomamos Ricoeur (2010b), para quem a ideia de tradição contém tensões entre as perspectivas de passado e presente, criando e transpondo noções de distâncias temporais. "Somos afetados pela história e afetamos a nós mesmos pelas histórias que fazemos" (RICOEUR, 2010b, p. 363). Nossa inserção no mundo constrói a história que constitui memória e cria novas tradições. As tradições não são estáticas nem estão presas em museus que tentam constantemente resgatar origens e formas puras das práticas culturais. Elas são vivas e emergem dos diálogos simbólicos que a memória produz. Ricoeur (2010b) conceitua a tradicionalidade como uma dialética entre inovação e sedimentação, que aponta para uma história viva, cujas referências são construídas nas narrativas pelas memórias que são articuladas. Deste modo, Ricoeur (2010b, p. 387) diferencia três conceitos: tradicionalidade; tradições e tradição.

1. Tradicionalidade é o encadeamento da continuidade que implica o nosso "serafetado-pelo-passado”, na dialética entre passado interpretado e presente interpretante a partir de uma "transmissão geradora de sentido” (RICOEUR, 2010b, p. 377);

2. Tradições são os conteúdos portadores de sentido que são transmitidos, "as coisas ditas no passado que chegaram até nós por uma cadeia de interpretações e reinterpretações” (RICOEUR, 2010b, p. 379);

3. Tradição está relacionada a uma presunção de verdade de um passado, a partir de proposições de sentidos, que aciona a memória coletiva.

As tradições, como elementos portadores de sentidos, são fundamentais para os processos comunicativos, sejam eles midiáticos ou não. E é como processo que pensamos o cordel: a partir da dimensão da tradicionalidade, das performances de tradições e da transmissão, da negociação e das relações de poder que se estabelecem a partir da ideia de manutenção de uma tradição “verdadeira”.

Esta ideia das transformações que seguimos aqui faz parte das discussões cotidianas de poetas que tentam definir o cordel, em busca de reconhecimento e legitimidade. Seja pela estrutura, pela forma, pelo suporte, há algo que precisa ser mantido e sustentado para que, no senso comum, se mantenha a tradição. “Adaptação como a tradução dos códigos, um jeito brasileiro de fazer e ler o folheto, que implicava na passagem por novos temas e por esse caráter de crônica, de um documento de História sob o ponto de vista não oficial, das camadas subalternas” (CARVALHO, 2002, p. 290).

Muitos fenômenos contemporâneos que se autodenominam de cordel são negados por grupos de poetas conservadores. Há níveis de conservadorismo entre poetas e 
estudiosos do fenômeno. Folcloristas, por exemplo, têm na ideia de tradição uma rigidez e consideram que as transformações descaracterizam os fenômenos, retirando-lhes a pureza e a originalidade. A própria Academia Brasileira de Literatura de Cordel mantém esse tom folclorista e engessador em suas publicações. Sendo o cordel uma poesia muitas vezes marginalizada, essa posição apenas contribui para manter uma segregação e hierarquização das formas de conhecimento.

Há também grupos de poetas e estudiosos que negam a perspectiva folclorista, mas que ainda mantém níveis de conservadorismo e exclusão - por exemplo, com relação às mulheres poetas, que não aparecem nas catalogações, como a da Fundação Casa de Rui Barbosa, de $19744^{4}$. Para esses poetas, por exemplo, não é problema usar a Internet para a circulação dos versos, ilustrar capas de folheto com imagens feitas por computador nem desassociar a poesia da xilogravura, mas permanecem defendendo que o cordel seja escrito e que obedeça a regras formais, classificando como "pé quebrado” aqueles cujas rimas destoam destas normas.

Há ainda quem questione essas definições e qualquer tipo de fixação: poetas que publicam folhetos com versos em formas livres, mulheres que usam a poesia como instrumento de luta feminista, movimentos de poetas que batem de frente com as estruturas pré-definidas por conservadores, estudiosos que tratam a poesia de cordel como forma de conhecimento e consideram a multiplicidade de usos da ideia de cordel por poetas e públicos. São estes que não costumam ser reconhecidos institucionalmente e são excluídos dentro de uma poesia que já é excluída dos cânones acadêmicos e literários.

Estes grupos não são de todo segregados, ainda que muitas vezes se contradigam. Tampouco são demarcados temporalmente, como observamos em Fonseca (2019, p. 202). Nessa pesquisa, foram encontrados três sentidos de tradição na poesia de cordel: aquela mais conservadora, associada à ideia de tradição com pretensões de verdade (RICOEUR, 2010b); uma segunda geração que não está totalmente de acordo com a primeira, e é composta por homens que propõem algumas inovações, desde que sejam mantidos os limites de seus privilégios sobre a narrativa do cordel; e a terceira geração, que seria composta por poetas que não se eximem de discutir questões de gênero, de etnias, de sexualidade e de outras normatividades no cordel. "A partir de uma proposta exaustiva de preservação do cordel, corre-se justamente o risco de levá-lo ao fim. Caso o cordel se torne anacrônico e perca seu valor de uso social, então, ele não terá mais motivo para existir” (FONSECA, 2019, p. 203).

Essa última geração é que, segundo Fonseca (2019) está mais motivada a puxar as transformações no universo do cordel. É possível identificar pessoas ligadas a cada uma das formas de compreensão da poesia de cordel, ou que em determinados momentos, de acordo com as conveniências, acionem posicionamentos de cada uma das categorias.

4 O primeiro grande estudo sobre a produção de mulheres poetas de cordel é o "Livro Delas”, que está em edição e é da autoria de Francisca Pereira dos Santos. 


\section{Rafael Brito: chamados de presente e de futuro do cordel}

Quando conheci o Maestro Rafael Brito pelo Facebook, vi o anúncio de uma declamação que ele faria no Centro Dragão do Mar, em Fortaleza, durante o festival Cordel com a Corda Toda. Entrei em contato com o organizador, Klevison Viana, para saber informações daquele nome novo, que eu ainda não tinha visto em nenhum outro evento que acompanhei. Klevison, então, me falou que aquele rapaz era "a grande promessa da poesia cearense”. Fiquei curiosa, adicionei aos amigos e puxei conversa, querendo saber mais sobre sua produção. Um tempo depois, nos vimos em uma declamação, mas não tivemos tempo para conversar. Mas aquela apresentação me chamou atenção. Pelo jovem poeta, provavelmente a pessoa de menos idade no auditório onde estávamos, mas também pela forma em que o público, composto em sua maioria por outros poetas - homens - respondia à apresentação. Ele vestia um terno verde escuro, usava um chapéu de vaqueiro e óculos escuros.

A produção artística e intelectual de Rafael Brito transita na interseção entre passado e presente, rural e urbano, e assim é reafirmada cotidianamente. Sua fala - identificada em entrevistas formais e em conversas não-estruturadas, além das observações de seu trabalho realizados em eventos em Fortaleza e em São Paulo - apresenta traços de apego a uma tradição que convoca o passado de experiências que não são dele, mas decorrem de memórias que, ao serem compartilhadas, são ressignificadas. A tradição, para o poeta, está relacionada aos modos de fazer que acionam uma tradição, por exemplo, o trabalho de Leandro Gomes de Barros ${ }^{5}$. Rafael reivindica, ainda, uma definição precisa da estrutura do cordel, porque foi essa a forma que ele aprendeu como a "correta”. Deste modo, ele se relaciona com a noção daquilo que Ricoeur (2010b) chama de “tradição” no singular, ou seja, uma pretensão de verdade importa por relações autoritárias de produção de memória.

Mas ele não cabe unicamente nesta definição, assim como o cordel que ele nos apresenta. O processo e aprendizagem poética que impõe formas fixas está no campo da tradição como elemento já elaborado e legitimado, transmitido entre pessoas de diferentes gerações. Mas como um artista de múltiplas habilidades, a performance poética de Rafael Brito também inclui a música, a interpretação e, o elo que nos traz aqui, a poesia. Ou seja, esse aprendizado formal do poeta é apenas um dos elementos que compõem as tradições e os processos de tradicionalidade constituintes de sentidos possíveis para o cordel.

Rafael é um jovem urbano que, em sua poesia, fala sobre outras realidades, muitas vezes experienciadas no Sertão. Sertão que é o cenário mais frequente para a poesia de cordel e é mais um elemento de tradição que ele carrega e reforça, ainda que não seja essa a sua vivência. É como se um poeta de cordel não pudesse prescindir de falar do Sertão ou da vida rural para entender-se como tradicional.

5 Considerado o pioneiro do folheto de cordel brasileiro. 
Sinto dentro da alma que tenho uma grandiosa responsabilidade com esse povo. Como poeta popular, escrevo e falo da vida deles como se fosse a minha própria. Sou embaixador desse povo, e me orgulho disso. Todas as histórias, todos os ditados, todos os costumes, as diferenças, tudo isso se torna combustível para os meus versos e me sinto feliz em saber que eles, aprovam (BRITO, 2017).

Sua poesia de cordel demanda uma aprovação de quem defende o tempo retomado em seus versos, seja nos temas, seja nas estruturas. O presente vivido por Rafael e suas experiências de consumo poético não são suficientes para que ele proponha mudanças estruturais no cordel ou que se desloque de modelos estabelecidos. Ele reforça o passado e é por ele legitimado. Só aí pode trazer essa poesia acionando tradições como conteúdos simbólicos. É, por exemplo, quando ele grava DVDs em estúdio e leva a rabeca, se apresenta com o figurino, leva o ritmo do cordel em poesias inéditas ou que ele interpreta de outros autores. Assim, ele performa uma tradição do cordel.

Sinto-me demasiadamente feliz por saber que mesmo não tendo vivido metade do que eles falavam, eles aprovavam a minha representação e receberam com orgulho o meu trabalho, mas o que mais me comoveu depois de ter terminado de declamar uma poesia, um deles olhar pra mim e dizer: Esse é poeta mesmo! (BRITO, 2017).

O poeta publica nas redes sociais - Facebook e Instagram - e divulga seu trabalho marcando seus amigos nas postagens. Envia seus trabalhos pelo Whatsapp. Tem um blog em que apresenta tanto poesia de cordel, como outras formas que seguem estruturas diferentes. Escreve sobre suas impressões do mundo, suas amizades, suas inspirações. Não está fora de ambientes midiatizados e nem pretende ficar. Rafael faz um elogio ao passado nos dias atuais. A partir do interesse que surge pela influência de seu avô, Rafael começou a buscar exercitar sua poesia declamando versos de outros poetas. Assistia às declamações, memorizava a poesia até conseguir encená-la - porque Rafael também é ator. Mas seu interesse fundamental está associado à música. Assim, por notório saber, ele ingressou no curso de Música da Universidade Federal do Ceará, onde estuda o violino. Mas pelas marcas da tradicionalidade identificadas em seus interesses culturais do "popular”, além do violino, Rafael aprendeu a tocar rabeca.

Esse diálogo entre a poesia do passado e os usos de equipamentos contemporâneos marca um trânsito de inovações que configuram a poesia de cordel na atualidade, com todos os embates que ele acarreta. Certamente, pode ter havido um movimento de cantadores, de poetas orais, que negassem a poesia impressa quando ela surgiu - como há quem ainda negue a validade dos versos na Internet. Mas a impressão foi aceita e reconhecida por seu caráter mercadológico: é mais fácil atribuir preço a um folheto do que à voz. Neste caso, continuaria sendo "a mesma poesia” oral, agora impressa. Mas aí ela assume outro nome: folheto (ou cordel, mais adiante). 
No caso do uso da digitalização e da circulação online, também continuam sendo "a mesma poesia” oral e impressa, mas agora com outro alcance, visibilidade e potencialidades técnicas decorrentes de suas materialidades e consequentes afetações.

O Maestro não chega a ter muitos folhetos, a forma mais "tradicional” do cordel, publicados. Seu trabalho é feito a partir de declamações que são gravadas, ou versos que circulam pela Internet, como já foi mencionado. Mas ainda é escrita e segue os padrões de estrutura exigida pelos pares que o validam. Neste caso, não há exigência do folheto. Pode até aparecer em livro. Mas não pode ser repente, porque não é oral. Não pode inovar, nem prescindir das rimas ou da métrica estabelecida.

O que aparece nos discursos de vários poetas - em palestras, entrevistas ou mesmo em conversas de bar - é uma rejeição de suportes que venham, por ventura, a sufocar a tão valiosa tradição. O presente é quase sempre marcado por eles como a negação do passado, como se o que se faz hoje não fosse também produto das relações com o passado, ou seja, daquilo que Ricoeur chama de tradicionalidade. Até que, depois de muitos embates, começa a haver uma aceitação e apropriação de suportes técnicos, que não modificam a poesia. Ela pode mudar e ainda assim manter-se tradicional, se pensamos nas tradições a partir dessa perspectiva processual e dialógica entre o passado e o presente, com vistas ao futuro.

Quanto a esse elemento que define a tradição não há consenso. Ainda não sabemos o que é que faz a poesia de cordel receber esse nome, que se mantém, historicamente, dentro de uma classificação definidora. Então, ainda que seja aceita a proximidade entre as formas poéticas, parece necessário dar nomes diferentes aos usos de outros suportes. A grande questão em torno da materialidade da poesia é que ela carrega sim uma grande diversidade de sentidos, somente podendo ser analisada individualmente. Não consideramos que a poesia oral é igual à poesia impressa, ainda que o texto seja o mesmo. Como tampouco têm as mesmas implicações e possibilidades dos versos que circulam pela Internet. Mas em vez de se pensar nessa diversidade como um devir, as discussões que são pautadas entre poetas ficam circunscritas a encaixar ou não uma poesia como cordel. É justamente por isso que não fechamos uma definição, mas propomos um olhar diverso que considere todas as formas que se apresentem ou que cotidianamente sejam chamados de "cordel”.

Pensamos a poesia de Rafael Brito como uma poesia contemporânea - sem entrar em definições do "contemporâneo" como conceito, mas considerando uma referência ampla de presente, cujo intervalo foi iniciado antes da escrita deste texto, e que não está encerrada. Nela, identificamos elementos de tradicionalidade, conforme proposta de Ricoeur (2010), ou seja, reconhecemos elementos de afetação do passado que não limitam as transformações possíveis de técnica, de forma, de suportes e lhes serve de base autoafirmativa.

Na historiografia da poesia de cordel, cuja morte já vem sendo anunciada desde Romero (1888) - e quando é negada acontece de forma apaixonada, feita por poetas que negam a morte futura a partir de suas próprias atividades - Rafael representa uma promessa aos seus antecessores. Ele é o jovem que “comprou” o legado e todos os seus desafios. Mas para que essa continuidade exista, ele não pode negar de todo o presente no qual vive, os 
meios técnicos aos quais tem acesso e facilidade e uso, tampouco poderia parar de dialogar a tradição com seus demais interesses artísticos. Para ser aceito e tratado como "a grande promessa” já mencionada nesse texto, ele não poderia transgredir demais, como fazem as jovens mulheres poetas de cordel, por exemplo. A vivência das tradições no presente só é possível quando consideramos os diálogos.

Como fenômeno narrativo, a história do cordel tem nos conceitos de tradição, tradições e tradicionalidade importantes elementos do círculo mimético de Ricoeur (2010). Em uma compreensão mais didática - porque estes elementos não estão tão separados por definições, mas se confundem nas práticas narrativas cotidianas - temos que a tradicionalidade está no campo da mímesis I, estando a afetação dos indivíduos, do cotidiano, da construção de compreensões no âmbito do mundo prefigurado, que será organizado em narrativas. É a carga simbólica do cordel. Que é memória, que traz as referências imagéticas da xilogravura, por exemplo, é a aura regional, identitária do cordel como poesia popular que permanece configurando os modos de compreensão desta poesia.

As tradições como os conteúdos portadores de sentidos são a própria tessitura da narrativa. O objeto folheto de cordel, por exemplo. Ou o texto que vem escrito e que é declamado da poesia. São muitos elementos que são acionados nas performances que, mesmo contemporâneas, legitimam-se em uma convocação de elementos do passado. A tradição, no singular, aparece no campo da mímesis 3. No movimento de leitura/audição/ consumo do folheto/da poesia. Transforma-se em tradição - com sua presunção de verdade, de conteúdo fechado - o conteúdo tomado como o definitivo. Mas que, de tão fluido, volta a ser elemento de tradicionalidade e, portanto, mimeses 1 . E o círculo mimético vai se movimentando em espiral.

A poesia do Maestro é dotada de uma tradicionalidade reconhecida no diálogo entre o passado e o contemporâneo. Ele parte de espaços de experiências já bem definidas, na qual ele se insere como um novo personagem da história. Essa poesia que ele aprende com o avô, que observa no poeta Chico Pedrosa e que toma inspiração em Jessier Quirino representa os elementos que vão construir a sua figura em performance: o músico clássico que aparece com um figurino matuto tocando rabeca e gravando DVD em estúdio.

O cordel de Rafael Brito é um acionamento das experiências do passado no presente. De uma tradição autoritária, como aquelas definidas pela ABLC e pela FCRB, segundo a proposta conceitual de Ricoeur (2010b). Há uma performance para defender esta tradição fixa, com elementos que não poderiam ser alterados (a métrica, a rima, o suporte), que se encontra com um presente cujas transformações são fundamentais para a tradicionalidade como processo simbólico e dialógico, e consequente transmissão das tradições. Estas são vivas quando experienciadas no presente com projeções de futuro, o que depende se sua capacidade de adaptação e maleabilidade para relacionar-se com outros fenômenos midiáticos, sociais, culturais.

Deste modo, Rafael Brito é uma possibilidade de presente que configura um horizonte de expectativas sobre o cordel, que deixa de ser o da morte. É a transição entre o passado 
de uma tradição e a promessa de continuidade dos elementos significativos, para que eles configurem uma constante afetação aos conteúdos do presente, com o objetivo de que eles permaneçam. São elementos como a estrutura narrativa dos romances de cordel, a forma poética com características muito rígidas de rima, de ritmo e de métrica e, principalmente, a distinção entre o que pode ser chamado de cordel e o que é o repente, uma disputa de sentidos que entre os poetas contemporâneos parece apaziguada, mas que continua repleta de conflitos.

A história de Rafael é importante para observarmos os espaços em que as tradições se manifestam na poesia de cordel, não apenas no que já conhecemos ao tratar o cordel como uma tradição do Nordeste brasileiro. Mas o trabalho de Rafael aponta para as noções de tradicionalidades como os efeitos de sentido do passado, sobre os quais se busca compreender e reforçar. Em um contexto que se reivindica o cordel como tradição - com seus traços e características definidores, muitas vezes, fechados - há um temor de que esses conteúdos se percam. Pelo tempo nele mesmo, ou pelo anacronismo de práticas e de consumos midiáticos que foram propostos na tentativa de definição fechada da poesia de cordel.

\section{Considerações finais ou as questões que ficam}

Para os demais poetas homens, Maestro Rafael Brito é uma esperança. É um contraponto ao temor de que a poesia chegue ao fim. Rafael representa uma continuidade. Que de uma forma muito conveniente, convoca as tradições, mas não nega as possibilidades midiáticas contemporâneas às quais tem acesso. Ele usa essas técnicas em uma medida que parece ser aceitável em um processo em que as inovações devem chegar devagar e dialogando com as repetições e, fundamentalmente, reconhecendo e reverenciando a tradição.

É como presente que Rafael é horizonte de expectativa. São as suas heranças culturais que prometem permanecer sendo difundidas, experienciadas. E para que essa tradição exista, ela precisa existir no presente e ser projetada em um devir. Rafael e outros jovens poetas representam isso. Mas isso não acontece sem contradições. A valorização de novos poetas segue a mesma linha de padrões excludentes. Além da manutenção da forma poética, as jovens mulheres poetas de cordel não têm a mesma visibilidade, senão por meios alternativos a este que já se diz alternativo a uma lógica hegemônica midiática e editorial.

Conceitualmente, nossa compreensão de tradições se choca com a reivindicação de alguns poetas que insistem em fixar a definição do cordel e de sustentar essas características como essenciais. Sendo que o passar tempo vem com transformações técnicas e usos culturais distintos que tornam certas práticas obsoletas se elas não forem reinventadas ou se elas não contribuírem para a reinvenção do cotidiano. Discordamos justamente por compreender que, ao manter fixa uma manifestação, ela será sufocada, portanto, tende a desaparecer.

O passado não precisa ser engessado, muito menos negado. O passado, como memória, afeta as ações do presente, como discutimos a partir da ideia de tradicionalidade. O passado é o campo das experiências, onde as tradições se formam e oferecem sentidos aos conteúdos 
do presente. Mas as transformações tampouco podem ser rejeitadas. As práticas culturais se sustentam no diálogo entre repetições e inovações. Da repetição, tira-se a referência, a memória. Das inovações, as propostas de continuidade. Rafael faz esse diálogo, mas ainda em muita sintonia com a ideia de tradição fixa, a qual ele teria o papel de manter.

Em nossa compreensão, o cordel contemporâneo precisa abrir espaço para as outras formas de fazer poesia, de publicar, de consumir. A historiografia oficial do cordel é contada em uma perspectiva patriarcal. Inclusive no cordel atual, que já aceita em certa medida a inserção de suportes técnicos, mas ainda organiza eventos se "esquecendo" das mulheres poetas, dos temas LGBTQIA+, focando sempre no que os homens dizem sobre as mulheres, ou em referências de "tolerância” em vez de discutir "respeito". As mulheres no cordel ainda são tratadas como um capítulo à parte, como uma excepcionalidade. E isso também representa as tradições poéticas do cordel, com as quais precisamos romper. Porque as mulheres sempre estiveram nos círculos poéticos do cordel, mesmo com a resistência dos homens. Que negam, que apagam e que fazem da sua própria narrativa a "tradição" com pretensões de verdade absoluta.

Esta é só uma das transformações que precisam ser pensadas e discutidas na escrita da historiografia do cordel. A juventude de Rafael nesse movimento de tradições mantidas e reescritas transita ainda em construção. Até aqui, há uma valorização do passado, mas que é impossível de negar o presente e as suas demandas. Por isso, Maestro Rafael Brito é uma expectativa de futuro do cordel. Buscando a tradicionalidade de sua obra, mas sem fechar-se para as transformações e as inovações necessárias em uma proposta que se configura como a continuidade da poesia de cordel.

\section{Referências}

ANTUNES, E. VAZ, P.B. Mídia: um aro, um halo e um elo. In: GUIMARÃES, C. Na mídia, na rua: narrativas do cotidiano. Belo Horizonte: Autêntica, 2006.

BRITO, R. Sertão Folhetim. Blog. Disponível em: http://sertaofolhetim.blogspot.com.br Acesso: 23 fev. 2018.

CARVALHO, G. Cordel, cordão, coração. Revista do GELNE (UFC), v. 4, p. 285-292, 2002.

CARVALHO, G. Tramas da Cultura: comunicação e tradição. Fortaleza: Museu do Ceará, 2005.

FONSECA, M. G. C. Novelo de verso: fios de memória, tradição e performance tecendo a poesia de cordel. Tese de doutorado. Belo Horizonte: UFMG, 2019.

FONSECA, M. G. C.; CARVALHO, C. A. Cordel e performance: o texto em ação no 'cordel com a corda toda’. Revista Latinoamericana de Ciencias de la Comunicación, v. 13, n. 25, 2017.

HAVELOCK, E. A. O oral e o escrito: uma reconsideração. In: HAVELOCK, E. A. A revolução da escrita na Grécia. São Paulo: Unesp; Rio de Janeiro: Paz e Terra, 1996.

HOBSBAWM, E.; RANGER, T. A invenção das tradições. Rio de Janeiro: Nova Fronteira, 2012.

LEMAIRE, R. Tradições que se refazem. Estudos de Literatura Brasileira Contemporânea, n. 35, p. 1730, 2010. 
LEMAIRE, R. Reler os textos: resgatar as vozes. In: FUNK, G. Estudos sobre Patrimônio oral. Câmara Municipa de Ponta Delgada. Açores. 2007.

LEMAIRE, R. Entre Oralidade e Escrita: as verdades da verdade, In: Actas do congresso Literaturas marginais, Porto, Ed. da Universidade do Porto, Portugal: 2008

ONG, W. Orality and Literacy: The tecnologizing of the word. London: Routledge, 1990.

RICOEUR, P. Tempo e Narrativa. Tomo I. São Paulo: Martins Fontes, 2010.

RICOEUR, P. Tempo e Narrativa: o tempo narrado. Tomo III. São Paulo: Martins Fontes, 2010b.

RICOEUR, P. A memória, a história, o esquecimento. Campinas: Unicamp, 2007.

RICOEUR, P. La lectura del tiempo pasado: memoria y olvido. Madrid: Ediciones de la Universidad Autónoma de Madrid. Arrecife, 1999.

ROMERO, S. Poesia popular do Brazil. Rio de Janeiro: Typografia Laemmert y Cia., 1888.

SILVA, G. Vertentes e evolução da literatura de cordel. Rio de Janeiro: Editora Ilart, 2014.

SILVA, M. et al. Literatura Popular em verso: estudos. Tomo I. Brasília: MEC; Rio de Janeiro: Fundação Casa de Rui Barbosa, 1973.

ZUMTHOR, P. Performance, Recepção, Leitura. São Paulo: Cosac Naify, 2014.

ZUMTHOR, P. Introdução à poesia oral. Belo Horizonte: UFMG, 2010.

\section{Maria Gislene Carvalho Fonseca}

Professora do Departamento de Jornalismo da Universidade Federal de Ouro Preto. Doutora em Comunicação Social pela Universidade Federal de Minas Gerais. Pesquisadora em estágio pósdoutoral no Programa de Pós-graduação em Comunicação Social (UFMG). Autora da tese "Novelo de verso: fios de memória, tradição e performance tecendo a poesia de cordel”. E-mail: mgisacarvalho@ gmail.com.

Recebido em: 07.08.2019

Aprovado em: 01.09.2020

Este artigo é publicado em acesso aberto (Open Access) sob a licença Creative Commons Attribution Non-Commercial (CC-BY-NC), que permite uso, distribuição e reprodução em qualquer meio, sem restrições, desde que sem fins comerciais e que o trabalho original seja corretamente citado.

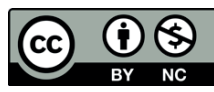

